\title{
DIREITO E A HISTÓRIA DA VINGANÇA DIVINA, PRIVADA E PUBLICA
}

Ismael de Oliveira Assis

Universidade do Oeste Paulista - UNOESTE, Curso de Direito, Presidente Prudente, SP. E-mail: oliverismael@hotmail.com

\section{RESUMO}

O presente estudo tem por objetivo, analisar o Direito nas suas fases de vingança e os resultados de sua adoção. Para compreender melhor o tema proposto, foi fornecido leve base introdutória do Direito. O trabalho também trata de incutir no estudioso do Direito, ou nos estudiosos leigos sobre o assunto os conhecimentos sobre esse período, com auxílio de pertinentes doutrinas da área jurídica e até mesmo, com a base de conhecimentos variados. As fases da vingança do Direito Penal foram amplamente aceitas ao seu tempo e representaram a depender do caso grandes inovações. Contudo seu caráter religioso, autoritário e suas sanções que violaram os Direitos mais básicos do homem, significaram um grande risco e perigo para o desenvolvimento sadio da sociedade.

Palavras-chave: Direito. História. Fases da Vingança. Lei de Talião. Composição.

\section{RIGHT AND THE HISTORY OF DIVINE, PRIVATE AND PUBLIC REVENGE}

\begin{abstract}
The present study aims to analyze the Law in its revenge phases and the results of its adoption. In order to better understand the proposed theme, a slight introductory basis of Law was provided. The work also tries to instill in the student of Law, or in lay scholars on the subject the knowledge about this period, with the aid of pertinent legal doctrines and even, with the base of varied knowledge. The phases of revenge of the Criminal Law were widely accepted in their time and represented depending on the case great innovations. Yet its religious, authoritarian character and its sanctions that violated man's most basic Rights, posed a great risk and danger to the healthy development of society.
\end{abstract}

Keywords: Law. History. Phases of Revenge. Law of Talião. Composition. 


\section{INTRODUÇÃO}

O atual trabalho apresenta relevante importância social, na medida em que fornece conhecimentos históricos do Direito, e mais precisamente dados sobre as fases de vingança. A importância da história não pode ser negada pois ela nos fornece elementos para a construção do presente, e previsão racional para o futuro. Nessa obra foi usada vasta bibliografia doutrinaria e literatura universal que trata sobre o assunto pertinente. O objetivo desta deste trabalho é analisar o Direito primitivo nas suas três fases, vingança divina, vingança privada e vingança pública e as eventuais consequências de sua vigência. É conhecendo melhor o passado que podemos nos preparar para possíveis riscos de retrocesso jurídico.

\section{METODOLOGIA}

O estudo teve por base pesquisas bibliográficas, leituras e fichamentos, para tal valeu-se da metodologia dedutiva. A delimitação do tema foi realizada com base na pertinência do assunto, bem como na finalidade objetivada, sendo que os conhecimentos prévios juntamente com as fontes de pesquisa disponíveis balizaram a profundidade da abordagem.

\section{A SOCIEDADE}

O ser humano não existe para viver só, a própria sobrevivência humana pressupõe parceria. Aonde quer que haja uma pessoa, haverá sempre a participação de uma outra, quer ele queira quer não. Foi exatamente sobre isso que Aristóteles (2001), preceituava ao dizer que o fundamento do homem é na política.

\section{DIREITO PENAL E A SOCIEDADE}

A relação social e Interdependência humana é, segundo Luiz Regis Prado (2006), da natureza do próprio homem, ou seja, o ser humano vive e sobrevive em agrupamentos. Pode ocorrer, porém que essa mesma relação coletiva represente também ameaça ou perigo, já que cada pessoa espera satisfazer a si próprio de acordo com os seus ideais. É para garantir a convivência harmoniosa, retribuir e prevenir o mau causado pelo infrator que o próprio corpo social, dotado de inteligência e perspicácia criou e desenvolveu seu sistema de leis penais, e expressou nesse sistema legal o que se espera de cada membro da sociedade, e as consequências de eventuais violações de Direitos.

\section{O DIREITO PENAL É DINAMICO}

$\mathrm{Na}$ atualidade, podemos conceituar o Direito Penal como: "complexo de preceitos legais que definem os crimes e determinam as penas e medidas de segurança, aplicáveis aos delinquentes" (Hildebrand. 2004 p. 112.)

O Direito, e mais especificamente a disciplina de Direito Penal, é suscetível a mudanças, não é como a estátua da deusa Themis, escultura de Alfredo Ceschiatti que adorna a fachada do STF. A norma jurídico-penal é dinâmica e mutável, pois é o produto racional do poder legislativo, que representa os mais relevantes anseios da sociedade. Porém nos primórdios dos tempos a realidade jurídica era outra, a mistura do Direito penal com a religião transformava aquele em uma espécie de dogma. (Coulanges 2006).

O Direito nesse período tinha um caráter sagrado, e era isso que impossibilitava mudanças radicais na lei. Mas quando eventualmente ocorria alguma transformação na norma, esta era tão ínfima e pouco perceptível que daí veio a ideia de imutabilidade da lei. O maior perigo em relação as novas leis, não era os seus pequenos acréscimos legais, mas sim o sacrilégio da revogação da norma anterior. (Coulanges, 2006 p.209). 


\section{FASES DO DIREITO PENAL}

Na doutrina a história do Direito Penal possui sua divisão em fases. E segundo Cleber Masson (2017) são elas: vingança divina, vingança privada e vingança pública.

Essas fases históricas não seguem uma ordem sequencial, conforme a maneira taxada acima, essa exposição é meramente didática, pois no curso da história elas muitas vezes surgiam de forma desordenada ou até mesmo sem uma sequência certa. A semelhança entre todas essas fases está no compromisso com a religião e o misticismo, ou seja, o abandono da razão, pela adoção de crenças frágeis e muitas vezes com consequências brutais, desproporcionais e sem um mínimo de fundamento. Aqui as penas de retribuição são muitas vezes cruéis e desiguais. $O$ que diferencia esses períodos, é que cada qual tem particularidades e elementos próprios de sua época ou sociedade, o que faz reafirmar a mutabilidade legal do Direito Penal.

\section{CONCEITO DE VINGANÇA}

Segundo Aurélio Buarque (2011), o termo vingança tem o sentido próprio de punição ou de castigo. Vingar significa também, promover a reparação.

\section{DA VINGANÇA DIVINA}

Nessa fase do Direito Penal, os lesados pelo infrator da lei são sempre os entes divinos ou sobrenaturais (normalmente os totens ou tabus), quer seja de forma direta ou indireta. A sociedade se agrupa, em torno de um sacerdote ou representante divino, que são intermediários entre a deidade e o corpo coletivo. A atividade legiferante não cabe a esse representante, mas sim ao próprio ente divino ou sobrenatural que revela diretamente toda sua diretriz máxima e inflexível ao seu povo. É em torno da revelação jurídica que toda sociedade se estrutura.

Diante desta realidade, Cleber Masson (2017), ensina que a pena nessa fase não tem caráter retributivo, mas de meramente expiação. $O$ transgressor da lei divina deveria ser punido pelos próprios membros do agrupamento, pois só assim todo pecado lançado sobre a sociedade seria perdoado.

Os totens e tabus aqui são figuras frequentes nas modalidades de pena. Segundo o supracitado autor, os totens tinham diversas aparências, poderiam ser representados por figuras de vegetal, animal, ou objetos e símbolos. Havia a separação do profano com o sagrado, e uma vez definido o profano esse não poderia mais manter relações com o sacro, e sequer com objetos religiosos, sob pena de castigo divino caso procedesse de forma contraria. (MASSON. 2017).

Nessa fase os membros da coletividade eram inteiramente vinculados por uma terceira figura, o Totem (estatuas de animais ou vegetais) e era essa mesma ligação totem-sociedade que possibilitava a sanção ao infrator do tabu. O sagrado e misterioso é a definição própria do termo tabu, (NUCCl, 2014.)

Digno de observação é notar que como a lei Penal era religiosa, sua sanção estava ligada a finalidade de satisfazer a entidade divina. Toda sociedade deveria participar da execução, como forma de expiar o mau causado pelo delinquente. As penalidades eram babaras, desiguais e desumanas. As punições mais comuns eram o desterro e a perda da paz.

Sobre a legislação dessa fase, preceitua Estefam e Gonçalves (apud SMANIO; FABRETTI, 2012, p.55) "as principais codificações dessa época foram o Código de Manu (Índia), Cinco Livros (Egito), Livro das Cinco Penas (China), Avesta (Pérsia), Pentateuco (Hebreus), entre outros".

\section{DA VINGANÇA PRIVADA}

Nesse período, os membros de cada família são ligados pela consanguinidade. O vínculo de sangue é suficientemente forte para o uso da vingança, deste modo cada membro familiar era como um só. (NUCCl, 2014, p. 54). 
Sendo unidos por um ancestral comum qualquer lesão causada por um membro de um clã diferente, autorizava o clã lesionado a se vingar contra o agressor ou qualquer de seus membros, posses e até mesmo a depender do caso contra todo o clã rival.

Era certo que a desproporcionalidade, crueldade e o ciclo de vingança era interminável, pois era comum o parente do agressor morto se vingar novamente de quem buscou justiça. 0 propósito da vingança privada é tão somente a retribuição do mal causado (GRECO, 2017, p.48), e por se tratar de justiça com as próprias mãos era desnecessário um terceiro intermediador na aplicação da punição. O que imperava era a lei do mais forte (MASSON, 2017, p.75).

Preceituam Estefam e Gonçalves (2012 pág. 55), que as penas mais comuns nessa fase eram: para os membros do próprio grupo a perda da paz, que nada mais é do que o banimento e a ausência de proteção da comunidade, e para os clãs rivais cabia a vingança de sangue. Essa modalidade de vingança, posteriormente sede lugar a Lei de Talião. A vingança penal pode até certo ponto parecer o ideal, principalmente em tempos como os nossos, em que a mídia sensacionalista nos enfia (desestimula a pensar) matérias prontas e com teor demasiado emotivo, e em alguns casos com conteúdo até mesmo duvidoso. Porém a história comprova que essas medidas não deram certo e nunca vão dar, pois falta transparência e sobretudo um olhar atento ao valor da dignidade humana, inerente ao ser pensante.

Hoje a autotutela, ou vingança pessoal não é vista com bons olhos pelo Direito Penal, muito embora haja exceções no ordenamento jurídico como a própria legitima defesa, a regra é a utilização da tutela jurisdicional do Estado, ou melhor dizendo do jus puniendi que é o direito privativo Estatal de punir (FLORENCIO, 2003, p. 259).

Mas esse tipo de modalidade infelizmente ainda é presente em algumas civilizações e em muitas áreas periféricas de atuais cidades (com sistema de lei não oficial vigorando paralelamente ao do Estado), e por onde ela passa deixa marcas irreparáveis. Por mais que se tente suprimir tal pratica, distante estamos de seu fim.

\section{DA VINGANÇA LIMITADA - LEI DO TALIÃO}

Conforme preceitua Cleber Massom (2017), a Lei do Talião tem sua origem no termo latino Talis que significa tal qual. O termo, Olho por olho, dente por dente, resume bem a base legal da lei do Talião, pois mostra valor de medida proporcional da lesão e pena. Surgiu como resposta as penas desiguais, e impessoais da época. O alto risco de aniquilação de todo um clã era crescente e não poderia passar despercebido (ESTEFAM; GONÇALVES, 2012, p. 55), era preciso adotar uma outra medida penal para resolver esse problema. O Talião veio com tudo para solucionar essas questões, introduzindo inovações como, as bases do princípio da proporcionalidade (GRECO, 2017, p.48) e princípio da individualidade da pena. Tamanho foi seu avanço para a época, que não passou despercebido nas legislações de diversos povos.

É fato de que as penas de retribuição equivalente, de efeito perpetuo, como as cruéis, e homicídios (a título de exemplo) podem até certo ponto parecer um ganho, porém seu uso é destrutivo, e nos dias de hoje seria um claro retrocesso contra os Direitos humanos. Nosso sistema prisional está longe da perfeição, sendo impossível afirmar com toda certeza que aqueles que cumprem pena são de fato culpados. Essa modalidade de pena ainda hoje é muito comum em países do oriente médio, ou onde o autoritarismo e o despotismo se fazem muito presente. Punir fisicamente com rigor está longe do ideal, tal pratica revela antes de tudo, não a justiça, mas o alto comando e ordem do Estado e mera subordinação de seu povo.

\section{DA COMPOSIÇÃO}

Apesar de a Lei de Talião ser amplamente aceita em seu tempo (MASSON,2017, p.76) os efeitos da pratica rígida da lei de talião se mostraram em longo prazo insuficientes para manutenção de uma cidade sadia, isso pelo fato de que as inúmeras lesões graves da população 
prejudicavam tanto a defesa quanto o desenvolvimento do país, o resultado disso tudo foi a incapacidade física de boa parte do grupo. Era hora de se criar outra medida. Foi então que surgiu a composição, esse termo provem de compositio que é a prestação pecuniária como forma de reparar o dano.

A Pena agora passou a atingir o capital do infrator em benefício do lesado. O Estado nesse sistema atua diretamente entre as partes a fim de resolver os conflitos, estipula também um sistema de tabelas que define o valor (Quantum) devidamente proporcional a cada perda, isso era adotado por exemplo pela Lei das 12 tabuas que previa a tarifa para composição. (ESTEFAM; GONÇALVES, 2012, p 56). A pratica restrita da composição como é caracterizada nessa fase, seria uma agressão direta aos princípios de direito natural do homem, visto que permitia a entrega de escravos, porém, seu desenvolvimento e aperfeiçoamento ligado a preocupação com a vida humana, traz inúmeros benefícios, como por exemplo a reparação material devida ao agredido, que na vingança limitada muitas vezes não caberia.

\section{DA VINGANÇA PÚBLICA}

A vingança pública é reflexo direto da evolução política e social. A sociedade agora tem uma estrutura muito mais complexa do que as fases anteriores, o Poder Público é central na vida da população que detém para si como meio de se manter no poder o ius puniendi. Nessa fase há a nítida intervenção Estatal, e o predomínio da proibição da autotutela é altamente presente. Cada cidadão fica obrigado a se sujeitar a tutela Jurisdicional Estatal para ter a garantia da justiça. Apesar do Estado intermediar a relação jurídico penal das partes, a sanção ainda mantém as características das outras demais fases, mostrando-se muitas vezes cruel e intimidatória, ainda havia a presença da religião e do misticismo e as penas variavam desde fogueira, esquartejamento até a amputação e castigos corporais. (MASSON, 2017, p.

$\mathrm{O}$ fato de qualquer Estado deter para si o poder incondicional sobre os demais, e usufruir livremente sem o controle devido, é um perigo. Não basta um Estado interventivo, é preciso haver limites.

\section{CONSTITUIÇÃO FEDERAL DE 1988}

O exercício da vingança e a desigualdade das sanções ante o delito, é coisa arcaica. A própria constituição Federal inclui um rol de Direitos fundamentais, com dispositivos legais que acabam e proíbem com as práticas violadoras de direitos fundamentais. $\mathrm{O}$ art. 5 da CF, por exemplo, contém inúmeros dispositivos da matéria de direito penal que objetiva resguardar a dignidade da Pessoa humana, entre eles estão: XL- Anterioridade da lei penal, XLVIindividualização da pena, XLV- proibição da punição passar da pessoa do condenado, XLVIIproibição de alguns tipos de sanções, que são as de banimento, prisão perpétua, de trabalhos forçados, morte, salvo em guerra declarada e cruéis (FILHO, 262).

A Constituição também preceitua que ninguém será processado ou julgado senão pela autoridade competente. Esses poucos exemplos demonstram a preocupação constitucional em evitar que haja retorno aos regimes repressivos e autoritários.

\section{LEGISLAÇÃO PENAL}

O nosso Código penal segue a diretiva da Constituição Federal, mais precisamente no sentido de reproduzir beneficamente inúmeros princípios constitucionais, como por exemplo o princípio da legalidade, anterioridade da lei, e talvez o mais relevante de todo, o princípio da humanidade, que nos dizeres de Nucci (2014): "O direito penal deve pautar-se pela benevolência, garantindo o bem-estar da coletividade, incluindo-se o dos condenados". Isso significa dizer também que penas de caráter cruel e perpetuo via de regra não serão adotadas pela legislação penal. 


\section{CONCLUSÃO}

Fica evidente pelo exposto nesse trabalho, que as fases de vingança possuem elementos comuns, trata-se da violação grave de Direitos fundamentais. O homem em tais períodos é a depender da civilização que se encontra, não mais que um animal doméstico. Muito embora algumas dessas fases tivesse grande aceitação popular ou representasse um certo avanço social para sua época, no contexto geral significou muito mais perdas do que ganhos. O ordenamento jurídico brasileiro por força constitucional não adere as fases de vingança. A adoção hoje desse corpo normativo religioso ou autoritário, significa muito mais o retrocesso do que avanço. Vivemos em um Estado Democrático de Direito pautado pela justiça, no qual o povo tem seu Direito resguardado, é sobre esse Direito, fruto da soberania popular que devemos nos guiar.

\section{REFERENCIAS}

ARISTÓTELES. Politica. 1.ed. São Paulo: Martin Claret, 2001. p 14.

COULANGES, NUMA. A cidade antiga. São Paulo: Martin Claret. 2006. p. 208.

ESTEFAM, A.; GONÇALVES, VICTOR. Direito penal esquematizado: parte geral. 2. ed. São Paulo: Saraiva. 2012. p.55-56.

FERREIRA, AURÉLIO. Dicionário escolar da língua portuguesa: aurélio júnior. 2. ed. Curitiba: Positivo. 2011. p. 907.

FILHO, MANOEL. Curso de direito constitucional. 22. ed. São Paulo: Saraiva. 1995. p. 262.

FLORENCIO, GILBERTO. Novo dicionário jurídico: de acordo com o novo código civil. 1. ed. São Paulo: Editora de direito, 2003. p. 259.

GRECO ROGERIO. Curso de direito penal: parte geral. 19. ed. Rio de Janeiro: Impetus. 2017. p. 48. HILDEBRAND, ANTONIO. Dicionário jurídico. São Paulo: Jhmizuno. 2004. p. 112.

MASSON, CLEBER. Direito penal esquematizado: parte geral. 11. ed. São Paulo: Método. 2017. p. 73, 75-76.

NUCCI, GUILHERME. Manual de direito penal: revista, atualizada e ampliada. 10. ed. Rio de Janeiro: Forense. 2014. p. 53-54, 63.

PRADO, LUIZ. Curso de direito penal brasileiro. 6. ed. São Paulo: Revista dos Tribunais. 2006. p. 49. 